\title{
Analisis Kesiapan Pembiayaan Hipertensi, Diabetes Melitus dan Gangguan Jiwa dalam Mendukung Program Indonesia Sehat dengan Pendekatan Keluarga (PIS PK) Tahun 2018-2020
}

\author{
Financing Readiness Analysis of Hypertension, Diabetes Mellitus and Mental Disorders \\ for the Healthy Indonesia with Family Approach Program, 2018 - 2020
}

\author{
Trihardini Sri Rejeki Astuti ${ }^{1}$, Prastuti Soewondo $^{2}$ \\ ${ }_{1}^{1}$ ascasarjana IImu Kesehatan Masyarakat, Fakultas Kesehatan Masyarakat, Universitas Indonesia, Depok, Indonesia \\ ${ }^{2}$ Departemen Administrasi dan Kebijakan Kesehatan, Fakultas Kesehatan Masyarakat, Universitas Indonesia, Depok, Indonesia
}

Korespondensi: Trihardini

e-mail: dini.drg@gmail.com

\begin{abstract}
Abstrak
Program Indonesia Sehat dengan Pendekatan Keluarga (PIS PK) merupakan cara Puskesmas untuk meningkatkan jangkauan sasaran dan akses pelayanan kesehatan dengan mendatangi keluarga. Skala prioritas nasional dalam mencapai Indonesia Sehat salah satunya adalah menanggulangi penyakit tidak menular termasuk hipertensi, Diabetes Melitus dan Gangguan Jiwa yang prevalensinya semakin meningkat. Hipertensi, Diabetes Melitus dan Gangguan Jiwa merupakan salah satu indikator keluarga sehat dalam PIS PK untuk mencapai SPM. Penelitian ini menggunakan metode kualitatif dengan teknik wawancara mendalam dan telaah dokumen. Kesiapan pembiayaan Hipertensi, Diabetes Melitus dan Gangguan Jiwa dihitung dengan menggunakan metode costing SPM. Hasil penelitian menunjukkan bahwa belanja kesehatan untuk PIS PK digunakan untuk sosialisasi, edukasi dan pendataan. Mengacu pada perhitungan costing SPM, Kota Depok mampu melaksanakan SPM untuk Pelayanan Dasar Hipertensi, Diabetes Melitus dan Gangguan Jiwa karena hanya menggunakan 1,38\% APBD Kesehatan Belanja Langsung (Non Gaji). Akan tetapi, Kota Depok belum siap dalam melaksanakan PIS PK dalam hal komitmen, SDM, dan anggaran. Kota Depok sudah memahami PIS PK namun pelaksanaannya tergantung pada ketersediaan pembiayaan yang berasal dari pencairan anggaran DAK Non Fisik. Hal ini disebabkan karena terdapat jeda waktu antara proses pengusulan dan realisasi pencairan anggaran sementara SDM terbatas. Diperlukan proses perencanaan yang lebih optimal serta pengalokasian SDM sesuai kebutuhan.
\end{abstract}

Kata kunci : Pendekatan Keluarga, SPM bidang kesehatan, Penyakit Tidak Menular, Pembiayaan kesehatan

\begin{abstract}
Healthy Indonesia Program with Family Approach (PIS PK) is a way to expand Puskesmas reach and access to health services through family home visit Overcoming non-communicable diseases (NCD) is a national priority in achieving Healthy Indonesia because the prevalence of NCD continues to increase. Managing NCD specifically hypertension, Diabetes Mellitus and mental disorders are among the indicators of healthy families in achieving PIS PK.This research uses the qualitative method through in-depth interviews and related document. Analysis of readiness of financing for hypertension, Diabetes Mellitus and mental is calculated using costing methode of SPM. The results indicated health spending for PIS PK activities were utilized for socialization, education and data collection. Referring to SPM costing calculation, the City of Depok was able to implement SPM for hypertension, Diabetes Mellitus and Mental Disorder with using only 1.38\% of the total APBD (non-salary). Depok City is not ready in implementing PIS PK, specifically in terms of commitment, human resources, and budget. Though already familiar with PIS PK, Depok City states due to its limited resources, PIS PK implementation depends on the availability of funding from Non-Physical DAK disbursement that tends to have a lengthy lag time between the proposal process and the realization of the disbursement. The financing of PIS PK requires a more optimal planning process and allocation of human resources as needed.
\end{abstract}

Keywords: Family Approach, Minimum Service Standards of Health, Non-Communicable Diseases, Health Financing

\section{Pendahuluan}

Program Indonesia Sehat dengan Pendekatan Keluarga (PIS PK) dilakukan dengan cara mengunjungi keluarga, dengan sasaran dan target PIS PK adalah keluarga. Pelaksanaan PIS PK bertujuan untuk meningkatkan akses pelayanan kesehatan dengan menggalakkan upaya promotif dan preventif. Pendekatan keluarga bertujuan meningkatkan akses keluarga terhadap pelayanan kesehatan yang menyeluruh, mendukung pencapaian Standar Pelayanan Minimal (SPM) kabupaten/ kota, mendukung pelaksanaan Jaminan Kesehatan Nasional (JKN), serta mendukung tercapainya 
program Indonesia Sehat (Kementerian Kesehatan, 2016a).

Banyak negara telah menerapkan konsep pendekatan keluarga atau dikenal dengan family approach dan di beberapa negara maju disebut sebagai primary health care (Ferdiansyah, 2016). Sebuah penelitian di India menyebutkan bahwa pendekatan yang berpusat pada keluarga yang mengekspos faktor penyakit kunci di luar perawatan konvensional akan memudahkan perawatan kesehatan berbasis kebutuhan dan memberikan solusi yang layak serta bertahan lama. Orientasi dan pelatihan petugas kesehatan tentang pendekatan keluarga ini sangatlah diperlukan (Shivalli, Majra, Akshaya, \& Qadiri, $2015)$.

Pada tahun 2018, pencegahan dan pengendalian PTM menjadi salah satu program prioritas nasional di bidang kesehatan. Penyakit PTM yang terus meningkat yaitu Hipertensi, Diabetes Melitus (DM) dan Gangguan Jiwa (Kementerian Kesehatan, 2016b). Keberhasilan PIS PK diukur dari Indikator Keluarga Sehat (IKS) yang dirumuskan dari 4 (empat) program kesehatan prioritas nasional di Indonesia yaitu menurunkan angka kematian ibu, menurunkan angka kematian bayi dan prevalensi stunting, mengendalikan penyakit menular khususnya HIV/AIDS, tuberkolosis dan malaria serta mengendalikan penyakit tidak menular (PTM) khususnya Hipertensi, Diabetes Melitus , kanker, obesitas dan Gangguan Jiwa (Kementerian Kesehatan, 2016a).

Empat program kesehatan prioritas ini, dalam program PIS PK diterjemahkan menjadi 12 Indikator Keluarga Sehat (IKS). Dari ke-12 indikator tersebut, terdapat 8 (delapan) indikator yang beririsan dengan pelayanan dasar yang ada di SPM, di mana dua di antaranya terkait PTM yakni pelayanan kesehatan penderita Hipertensi dan Gangguan Jiwa. Sehingga jika pendekatan keluarga ini dilaksanakan dengan baik maka salah satu tujuan pendekatan keluarga untuk meningkatkan capaian SPM kabupaten/kota akan tercapai.

Prevalensi PTM untuk Hipertensi, Diabetes Melitus dan Gangguan Jiwa di Depok menunjukkan angka yang relatif cukup tinggi, bahkan lebih tinggi daripada prevalensi di tingkat nasional (Tabel 1) (Badan Penelitian dan Pengembangan Kementerian Kesehatan, 2013). Jenis layanan dasar Hipertensi, Diabetes Melitus dan Gangguan Jiwa ini masuk dalam IKS dalam PIS PK dan layanan dasar SPM.
Tabel 1. Gambaran Prevalensi PTM

di Kota Depok tahun 2013

\begin{tabular}{lccc}
\hline \multirow{2}{*}{ No Indikator } & \multicolumn{3}{c}{ Prevalensi } \\
\cline { 2 - 4 } & $\begin{array}{c}\text { Kota } \\
\text { Depok }\end{array}$ & $\begin{array}{c}\text { Jawa } \\
\text { Barat }\end{array}$ & Indonesia \\
\hline 1. Diabetes $(\geq 15$ tahun) & $2,0 \%$ & $1,3 \%$ & $6,9 \%$ \\
\hline 2. Hipertensi ( $\geq 15$ tahun) & $25,8 \%$ & $29,4 \%$ & $25,8 \%$ \\
\hline $\begin{array}{l}\text { Gangguan Mental } \\
\text { 3. Emosional ODGJ ( } \geq 15 \\
\text { tahun) }\end{array}$ & $12,0 \%$ & $9,3 \%$ & $6,0 \%$ \\
\hline 4. Katarak (semua umur) & $0,6 \%$ & $1,5 \%$ & $1,8 \%$ \\
\hline $\begin{array}{l}\text { 5. Gangguan Pendengaran } \\
\text { ( } \geq 5 \text { tahun) }\end{array}$ & $1,4 \%$ & $2,5 \%$ & $2,6 \%$ \\
\hline 6. Ketulian ( $\geq 5$ tahun) & $0,1 \%$ & $0,1 \%$ & $0,09 \%$ \\
\hline 7. Kanker (semua Umur) & $\begin{array}{c}0,3 \text { per } \\
\text { mil }\end{array}$ & 0,1 per mil & $\begin{array}{c}1,4 \text { per } \\
\text { mil }\end{array}$ \\
\hline
\end{tabular}

Target kebijakan baku dari Pemerintah Pusat dengan capaian total coverage di tahun 2019 perlu dipantau. Berdasarkan data dashboard keluarga sehat, capaian IKS penderita Hipertensi yang berobat teratur di Provinsi Jawa Barat hanya sebesar 24,7\% dari target nasional sebesar 24,9\%. Data capaian IKS pelayanan ODGJ di Provinsi Jawa Barat sebesar $5,8 \%$, sementara tingkat nasional sebesar $8,8 \%$.

Secara nasional, IKS Indonesia adalah 0,156, jumlah keluarga yang dikunjungi sebanyak 3.928.651 keluarga dengan persentase 5,897\%, sementara Jawa Barat mempunyai IKS 0,117 dengan jumlah keluarga yang telah dikunjungi sebanyak 428.895 keluarga dengan persentase 3,357\%. Sementara kota Depok melakukan kunjungan keluarga sebanyak 3.555 keluarga dengan persentase 0,788\% berdasarkan data per Desember 2017 (Kementerian Kesehatan, 2017).

Rendahnya cakupan kunjungan keluarga dan IKS di Depok ini diduga disebabkan karena adanya kendala dan hambatan dalam hal keterbatasan anggaran, SDM, kesulitan input data dan manajemen teknis pendataan. Oleh karena itu diperlukan penelitian lebih lanjut tentang kesiapan pembiayaan pelaksanaan PIS PK di Depok dari sisi perencanaan, sumber daya manusia, dan pembiayaan.

\section{Metode}

Penelitian ini menggunakan desain kualitatif dengan metode Rapid Assesment Procedure (RAP) yang bertujuan untuk mengetahui kesiapan pembiayaan Hipertensi, Diabetes Melitus dan Gangguan Jiwa untuk mendukung pelaksanaan PIS PK di kota Depok tahun 2018-2020. Penelitian dilakukan di Dinas Kesehatan Kota Depok dan Puskesmas 
Cimanggis di kota Depok pada bulan April sampai Juni 2018. Penelitian ini menggunakan data primer yang diperoleh melalui wawancara mendalam dengan informan dan telaah dokumen terkait dan perhitungan kebutuhan biaya dengan menggunakan metode costing SPM.

Sumber informan dalam wawancara mendalam yaitu (1) Health Policy Unit Kementerian Kesehatan; (2) Kepala Seksi Pelayanan Kesehatan Primer Dinas Kesehatan kota Depok; (3) Kepala Seksi Perencanaan Evaluasi dan Pelaporan Dinas Kesehatan Depok; (4) Kepala Seksi Penyakit Tidak Menular Dinas Kesehatan Depok; (5) Pengelola program Penyakit Tidak Menular (PTM) Dinas Kesehatan Kota Depok; (6) Kepala Puskesmas Cimanggis; dan (7) Petugas aplikasi pendataan keluarga sehat di Puskesmas Cimanggis

Pengumpulan data sekunder diperoleh melalui dokumen-dokumen berupa telaah dokumen PIS PK dan PTM di Dinas Kesehatan Depok. Data yang dibutuhkan dalam menyisir belanja kesehatan PIS PK untuk Hipertensi, DM dan Gangguan Jiwa tahun 2018-2020 yaitu :

a. Data Renstra tahun 2016-2021

b. APBD Depok Tahun 2017 dan 2018

c. Laporan Realisasi Anggaran Dinas Kesehatan Kota Depok tahun 2017

d. Dokumen Pelaksanaan Anggaran Dinas Kesehatan Kota Depok tahun 2018

e. Profil Dinas Kesehatan Kota Depok tahun 2016-2017

f. Laporan realisasi dana DAK Non Fisik tahun 2017

g. Alokasi dana DAK Non Fisik tahun 2018

h. Daftar harga satuan kabupaten/kota

i. Daftar realisasi penggunaan obat dan bahan habis pakai pelayanan penyakit Hipertensi, Diabetes Melitus dan ODGJ

j. Daftar pengadaan alat medis dan non medis pelayanan penyakit Hipertensi, Diabetes Melitus dan ODGJ

\section{Hasil Penelitian}

\section{Komitmen dan Kebijakan Program}

Aspek komitmen pemerintah daerah pada penelitian ini menilai adanya kejelasan dan dukungan pemerintah daerah dalam pelaksanaan PIS PK. Komitmen pemerintah daerah pada PIS PK terlihat pada alokasi anggaran untuk PIS PK di kota Depok yang tercantum dalam Renstra Perubahan tahun
2019-2021. Sebelumnya tidak ada anggaran khusus di Renstra untuk pelaksanaan PIS PK. Disusunnya Renstra Perubahan tersebut membuktikan adanya komitmen Pemerintah Kota Depok terhadap program prioritas. Namun menurut salah satu informan, alokasi anggaran tersebut belum optimal karena banyak program prioritas yang juga memerlukan anggaran sehingga masih harus berbagi anggaran dengan program prioritas lain.

"Kalau dari komitmen, dari kebijakan sudah didukung, dari renstra sudah dimasukkan, karena ga semua program kita akomodir di renstra, tapi untuk PIS PK kita khususkan saat renstra kita masukkan dalam kegiatan tersendiri..."

"Komitmen Depok, kalo liat Dinkes mendukung sekali, karena semua masalah berbasis keluarga per wilayah, secara program dan intervensi. Karena Puskesmas BLUD, biar enak disepakati pake BOK. Kalo emang dana RBA BLUD mampu memback up, boleh pake BLUD. Yang jelas dari APBD tidak ada. Karena dari $A P B D$ hanya biaya operasional dan pegawai. Untuk UKP ke BLUD, UKM ke BOK..."

Saat ini belum ada regulasi setingkat kabupaten/ kota yang mengatur tentang PIS PK sedangkan Perwal tentang SPM sedang dalam proses akhir. Belum adanya regulasi tingkat kabupaten/kota ini menunjukkan kurangnya komitmen dari Pemerintah Kota bahwa Depok siap untuk mensukseskan suatu program atau kebijakan.

"Rencananya kan untuk PIS PK ada Perwal. Cuma kita juga belum mulai bikin draft perwalnya isinya tentang apa, karena itu penting supaya ada dasarnya. Untuk Dinas kesehatan sudah ada SK Kepala Dinas Kesehatan. Untuk tingkat puskesmas sudah diminta ada SK Kepala Puskesmas dengan dasarnya SK Kepala Dinas"

Pembentukan Seksi P3TM pada SOTK Dinas Kesehatan di tahun 2017 mengacu pada perubahan SOTK Kementerian Kesehatan yang baru yakni Permenkes Nomor 64 Tahun 2015. Hal ini berdasarkan fakta bahwa angka prevalensi PTM saat ini cukup tinggi di Depok bahkan di Indonesia, dan tren akan semakin meningkat. Demikian pula halnya dengan pelayanan kesehatan jiwa, yang semula berada di bawah bidang pelayanan kesehatan seksi Pelayanan Kesehatan Primer, berubah menjadi di bawah bidang Pencegahan dan Pengendalian Penyakit seksi Pencegahan dan Pengendalian Penyakit Tidak Menular (P3TM) sesuai SOTK baru yang mengacu 
pada perubahan SOTK Kemenkes. Hal tersebut menunjukkan bahwa Pemerintah Kota Depok mulai memberi perhatian lebih dalam pada penyakit tidak menular.

\section{Sumber Daya Manusia}

Aspek SDM pada penelitian ini berdasarkan kuantitas dan kualitas SDM yang melaksanakan PIS PK. Aspek SDM dalam pelaksanaan PIS PK ini meliputi kecukupan tenaga yang mengikuti pelatihan PIS PK dan melakukan pendataan PIS PK. Dalam hal sumber daya manusia, Pemerintah Kota Depok masih kekurangan SDM untuk melakukan pendataan PIS PK serta masih sedikitnya tenaga kesehatan yang mengikuti pelatihan. Kedua hal tersebut berkaitan erat dengan ketersediaan anggaran karena anggaran untuk pelatihan baru ada di APBD tahun 2019. Dana DAK Non Fisik yang ada tidak mengakomodir adanya pelatihan, hanya sebatas sosialisasi, monev dan pendataan. Untuk itu dapat dikatakan bahwa dari aspek SDM, Kota Depok belum siap melaksanakan kegiatan PIS PK.

"PIS PK kegiatannya seperti itu, sosialisasi dan pendataan, tidak ada pelatihan padahal itu yang paling penting. Itu ketentuan dari DAK, menunya seperti itu tidak boleh. "Inovasi yang dilakukan terkait SDM dilakukan dengan dana BLUD"

\section{Sistem Informasi Kesehatan}

Aspek sistem informasi kesehatan yang dilihat dalam penelitian ini adalah penggunaan web aplikasi keluarga sehat. Kota Depok mengalami kendala dalam hal input atau entry data dalam aplikasi keluarga sehat. Sejalan dengan penelitian Laelasari (2017), kendala serupa dialami pula oleh beberapa kabupaten/kota di samping keterbatasan sarana prasarana dan sinyal internet. Proses pendataan PIS PK di Depok belum dilakukan dengan optimal karena keterbatasan SDM, sistem informasi kesehatan dan dana.

Tahap intervensi lanjut belum dilakukan oleh karena proses pendataan belum selesai. Hambatan yang seringkali dialami oleh Kota Depok adalah kesulitan untuk masuk dalam web baik untuk input data maupun revisi data. Hal ini menyebabkan angka IKS serta cakupan keluarga yang telah dikunjungi yang tercantum di aplikasi masih cukup rendah. Jumlah pencapaian data keluarga Depok yang tercatat di aplikasi keluarga sehat Kemenkes per tanggal 16 Mei 2018 sebanyak 7.821 jiwa dengan data IKS 0,27 (Kementerian Kesehatan, 2017)

"Kendala pada aplikasi keluarga sehat, karena den- gan aplikasi Puskesmas langsung mendapat input berupa IKS keluarga. Kendala IKS tidak bisa muncul. Dengan adanya kendala, otomatis terhambat adalah hal analisanya, intervensinya sedangkan di sini kan untuk aplikasi bukan wewenang dinas kesehatan untuk utak atik. Harus koordinasi dengan pihak pusdatin, sementara Pusdatin tidak fast response. Itulah sebabnya data IKS Depok sangat rendah".

Tabel 2 menunjukkan bahwa IKS Kota Depok per tanggal 16 Mei 2018 masuk dalam kategori Keluarga Tidak Sehat. Indikator PTM yaitu Hipertensi dan Gangguan Jiwa (indikator 7 dan 8) menunjukkan baru $21 \%$ penderita Hipertensi berobat dengan teratur dan 20\% penderita Gangguan Jiwa berat diobati dan tidak ditelantarkan. Angka IKS Depok $=0,27$ berarti baru 27\% keluarga yang tergolong sehat.

\section{Ketersediaan Anggaran}

Dari hasil telaah dokumen, terlihat bahwa Depok memiliki ketersediaan anggaran yang cukup untuk pelaksanaan kegiatan yang menunjang PIS PK. Anggaran ini dipastikan akan terus bertambah dengan masuknya PIS PK sebagai kegiatan prioritas pada Renstra 2019-2021. Namun ketersediaan anggaran belum ada hingga penelitian ini dilakukan, memasuki tri wulan kedua, oleh karena sumber pembiayaan utama yang digunakan untuk pelaksanaan PIS PK berasal dari DAK Non Fisik sementara realisasi anggaran DAK Non Fisik Tahun 2018 terlambat. Prediksi anggaran DAK Non Fisik yang diterima dan akan digunakan untuk menunjang kegiatan PIS PK sebesar Rp 435.056.000.

\section{Perencanaan}

Hasil wawancara mendalam menyebutkan bahwa Pemerintah Kota Depok telah merencanakan kegiatan PIS PK dalam Renstra Perubahan tahun 20192021. Proses perencanaan di Depok yang menggunakan kombinasi top down dan botton up approach mengacu pada dokumen-dokumen Renstra. Namun dalam kenyataannya, terdapat Peraturan Pemerintah dan Permenkes yang terbit setelah Musrenbang selesai dilaksanakan di akhir bulan Maret.

Hal ini memperlihatkan perencanaan yang dilakukan tidak optimal Meskipun anggaran untuk pelaksanaan jenis pelayanan dasar Hipertensi, Diabetes Melitus dan Gangguan Jiwa cukup, namun karena hampir semua pembiayaan bersumber dari dana DAK Non Fisik, maka terdapat kendala-kendala yang akan berpengaruh besar pada perencanaan. Siklus perencanaan dana DAK Non Fisik berbeda dengan siklus perencanaan APBD. 
Tabel 2 Gambaran Indikator Keluarga Sehat Depok per 16 Mei 2018

\begin{tabular}{|c|c|c|c|}
\hline No & Indikator & $\begin{array}{c}\text { \% Cakupan } \\
\text { Depok }\end{array}$ & $\begin{array}{l}\text { \% Cakupan } \\
\text { Jawa Barat }\end{array}$ \\
\hline \multirow[t]{3}{*}{1} & Keluarga mengikuti program $\mathrm{KB}^{\star}$ ) & $38,4 \%$ & $39,6 \%$ \\
\hline & $\sum$ Keluarga Bernilai Y & 2.530 & 370.586 \\
\hline & $\sum$ Keluarga- $\sum$ Keluarga bernilai "N" & 6.586 & 936.262 \\
\hline \multirow[t]{3}{*}{2} & Persalinan Ibu di fasilitas pelayanan kesehatan & $91,4 \%$ & $88,2 \%$ \\
\hline & $\sum$ Keluarga Bernilai Y & 363 & 38.332 \\
\hline & $\sum$ Keluarga- $\sum$ Keluarga bernilai "N" & 397 & 43.477 \\
\hline \multirow[t]{3}{*}{3} & Bayi mendapatkan imunisasi dasar lengkap ${ }^{\star}$ ) & $91,8 \%$ & $92,8 \%$ \\
\hline & $\sum$ Keluarga Bernilai Y & 358 & 43.823 \\
\hline & $\sum$ Keluarga- $\sum$ Keluarga bernilai "N" & 390 & 47.213 \\
\hline \multirow[t]{3}{*}{4} & Bayi mendapatkan ASI Eksklusif & $81,1 \%$ & $84,8 \%$ \\
\hline & $\sum$ Keluarga Bernilai Y & 420 & 54.972 \\
\hline & $\sum$ Keluarga- $\sum$ Keluarga bernilai "N" & 518 & 64.847 \\
\hline \multirow[t]{3}{*}{5} & Pertumbuhan Balita dipantau & $91,4 \%$ & $92,3 \%$ \\
\hline & $\sum$ Keluarga Bernilai Y & 1.500 & 214.490 \\
\hline & $\sum$ Keluarga- $\sum$ Keluarga bernilai "N" & 1.642 & 232.462 \\
\hline \multirow[t]{3}{*}{6} & Penderita TB Paru yang berobat sesuai standar & $51,5 \%$ & $41,4 \%$ \\
\hline & $\sum$ Keluarga Bernilai Y & 176 & 18.146 \\
\hline & $\sum$ Keluarga- $\sum$ Keluarga bernilai "N" & 342 & 43.877 \\
\hline \multirow[t]{3}{*}{7} & Penderita Hipertensi yang berobat teratur & $21,0 \%$ & $23,8 \%$ \\
\hline & $\sum$ Keluarga Bernilai Y & 414 & 69.820 \\
\hline & $\sum$ Keluarga- $\sum$ Keluarga bernilai "N" & 1.968 & 293.171 \\
\hline \multirow[t]{3}{*}{8} & Penderita Gangguan Jiwa berat, diobati dan tidak ditelantarkan & $20,0 \%$ & $11,6 \%$ \\
\hline & $\sum$ Keluarga Bernilai Y & 24 & 2.334 \\
\hline & $\sum$ Keluarga- $\sum$ Keluarga bernilai "N" & 120 & 20.171 \\
\hline \multirow[t]{3}{*}{9} & Anggota keluarga tidak ada yang merokok ${ }^{*}$ ) & $55,0 \%$ & $34,2 \%$ \\
\hline & $\sum$ Keluarga Bernilai Y & 4.300 & 401818 \\
\hline & $\sum$ Keluarga- $\sum$ Keluarga bernilai "N" & 7.821 & 1.175 .648 \\
\hline \multirow[t]{3}{*}{10} & Keluarga sudah menjadi anggota JKN & $70,8 \%$ & $43,6 \%$ \\
\hline & $\sum$ Keluarga Bernilai Y & 5.534 & 511.761 \\
\hline & $\sum$ Keluarga- $\sum$ Keluarga bernilai "N" & 7.812 & 1.173 .384 \\
\hline \multirow[t]{3}{*}{11} & Keluarga memiliki akses/menggunakan sarana air bersih & $98,8 \%$ & $96,8 \%$ \\
\hline & $\sum$ Keluarga Bernilai Y & 7.714 & 1.134 .880 \\
\hline & $\sum$ Keluarga- $\sum$ Keluarga bernilai "N" & 7.811 & 1.172 .386 \\
\hline \multirow[t]{6}{*}{12} & Keluarga memiliki akses/menggunakan jamban keluarga & $98,3 \%$ & $94,4 \%$ \\
\hline & $\sum$ Keluarga Bernilai Y & 7.676 & 1.105 .828 \\
\hline & $\sum$ Keluarga- $\sum$ Keluarga bernilai "N" & 7.810 & 1.171 .886 \\
\hline & Indeks Keluarga Sehat (IKS) & 0,270 & 0,13 \\
\hline & $\Sigma$ Keluarga dengan IKS $>\mathbf{0 , 8 0 0}$ & 2.110 & 153.007 \\
\hline & $\sum$ Keluarga & 7.821 & 1.175 .648 \\
\hline
\end{tabular}

Dana DAK Non Fisik merupakan bagian dari dana transfer sehingga belum tersedia di awal tahun anggaran. Namun saat pelaksanaan Musrenbang dan penetapan dana APBD seringkali Kota Depok belum mengetahui jumlah anggaran yang diperoleh untuk pelaksanaan SPM. Proses DAK Non Fisik ini dimulai sejak bulan Januari dan pencairan baru terealisasi di bulan April untuk tahun lalu dan akhir Mei tahun 2018. Hal ini tentu saja menyebabkan sisa waktu yang ada semakin sedikit, sehingga berbagai kegiatan dipadatkan sementara SDM terbatas.

\section{Peta Jalan Pelaksanaan PIS PK}

Di tingkat Dinas Kesehatan Kabupaten/Kota, pelaksanaan PIS PK dilakukan mulai dari tahap sosialisasi, pendataan, intervensi awal, intervensi lanjut dan monitoring dan evaluasi. Berdasarkan hasil wawancara mendalam, Pemerintah Kota Depok menerapkan peta jalan pelaksanaan PIS PK secara bertahap untuk mencapai target pendataan 100\% di tahun 2019.

Pelaksanaan pendataan dilakukan di Depok mulai tahun 2017 di Puskesmas Cimanggis, yang menjadi lokus Kementerian Kesehatan. Pada tahun 2018, target 50\% KK terdata dari masing-masing Puskesmas di Depok dan sisanya 50\% selesai di tahun 2019. Secara bertahap PIS PK ini akan dilaksanakan di 35 Puskesmas yang ada di kota Depok sampai dengan tahun 2019. 


\section{Realisasi Anggaran}

Pembiayaan PIS PK di Depok belum berjalan optimal karena keterlambatan realisasi dana DAK Non Fisik sementara dana yang digunakan untuk mendukung pelaksanaan kegiatan PIS PK berasal dari DAK Non Fisik. Hal ini disebabkan karena Permenkes Nomor 61 Tahun 2017 tentang Petunjuk Teknis Penggunaan Dana DAK Non Fisik baru terbit di bulan Desember 2017 sesudah penetapan APBD. Oleh karena itu dana DAK Non Fisik di Kota Depok mengalami pergeseran dan memerlukan proses verifikasi yang cukup lama. Dari hasil telaah dokumen didapatkan bahwa alokasi dana PIS PK yang ada di Puskesmas dan Dinas Kesehatan Kota Depok untuk membiayai kegiatan-kegiatan yang menunjang pelaksanaan PIS PK berupa sosialisasi, pendataan, honorarium dan monitoring dan evaluasi.

"Tahun ini belum ada DPA khusus untuk PIS PK, baru tahun depan. Alokasi anggaran paling kita dari BOK, Cuma dari BOK dari segi jumlah kita meningkat, Protap otonomi daerah, uang masuk APBD daerah, mau tidak mau kita harus ikuti prosedur yang ada di APBD, kita harus lintas sektor. Sehingga ke depannya harus banyak-banyak koordinasi dan gerak, nanyain ke BKD, Setda dan Bappeda".

Tabel 3 menjelaskan bahwa 25,85\% dari total dana DAK Non Fisik yang diterima oleh Dinas Kesehatan dan Puskesmas Kota Depok dialokasikan untuk kegiatan yang menunjang pelaksanaan PIS PK, yaitu sebesar Rp 4.245.892.000. Anggaran yang menunjang kegiatan PIS PK tersebut hanya berupa sosialisasi dan pendataan serta monev secara umum, dan tidak ada anggaran untuk intervensi pelayanan PTM di dalam pelaksanaan PIS PK.

Dari hasil pendataan keluarga tersebut, akan diketahui jumlah kasus PTM yang ada di kota Depok, sehingga dapat diketahui jumlah biaya yang harus dikeluarkan oleh kota Depok dalam pelayanan kesehatan PTM sesuai hasil costing SPM. Hasil pendataan keluarga akan disampaikan kepada masing-masing program, agar dapat segera dilakukan intervensi yang tepat, karena PIS PK merupakan integrasi program yang telah ada.

Tabel 3 Jumlah Dana DAK Non Fisik yang mendukung kegiatan PIS PK

\begin{tabular}{|c|c|c|c|}
\hline \multirow[b]{2}{*}{ Jenis Kegiatan } & \multicolumn{2}{|c|}{ Jumlah Dana } & \multirow{2}{*}{$\begin{array}{c}\text { Total Dana } \\
\text { DAK Non Fisik }\end{array}$} \\
\hline & $\begin{array}{c}\text { Kegiatan yang } \\
\text { Mendukung PIS PK }\end{array}$ & Lainnya & \\
\hline $\begin{array}{l}\text { Pengelolaan Manajemen Pemanfaatan } \\
\text { BOK Tingkat Kota }\end{array}$ & 379.107 .000 & 292.471 .000 & 671.578 .000 \\
\hline $\begin{array}{l}\text { Pelayanan Kesehatan Dasar di Puskesmas } \\
\text { Kecamatan Sukmajaya }\end{array}$ & 404.950 .000 & 1.095 .050 .000 & 1.500 .000 .000 \\
\hline $\begin{array}{l}\text { Pelayanan Kesehatan Dasar di Puskesmas } \\
\text { Kecamatan Cimanggis }\end{array}$ & 404.950 .000 & 1.095 .050 .000 & 1.500 .000 .000 \\
\hline $\begin{array}{l}\text { Pelayanan Kesehatan Dasar di Puskesmas } \\
\text { Kecamatan Pancoran Mas }\end{array}$ & 289.086 .000 & 1.210 .914 .000 & 1.500 .000 .000 \\
\hline $\begin{array}{l}\text { Pelayanan Kesehatan Dasar di Puskesmas } \\
\text { Kecamatan Beji }\end{array}$ & 440.286 .000 & 759.714 .000 & 1.200 .000 .000 \\
\hline $\begin{array}{l}\text { Pelayanan Kesehatan Dasar di Puskesmas } \\
\text { Kecamatan Tapos }\end{array}$ & 53.200 .000 & 1.346 .800 .000 & 1.400 .000 .000 \\
\hline $\begin{array}{l}\text { Pelayanan Kesehatan Dasar di Puskesmas } \\
\text { Kecamatan Cilodong }\end{array}$ & 637.275 .000 & 412.725 .000 & 1.050 .000 .000 \\
\hline $\begin{array}{l}\text { Pelayanan Kesehatan Dasar di Puskesmas } \\
\text { Kecamatan Sawangan }\end{array}$ & 354.535 .000 & 645.465 .000 & 1.000 .000 .000 \\
\hline $\begin{array}{l}\text { Pelayanan Kesehatan Dasar di Puskesmas } \\
\text { Kecamatan Bojongsari }\end{array}$ & 470.367 .000 & 579.633 .000 & 1.050 .000 .000 \\
\hline $\begin{array}{l}\text { Pelayanan Kesehatan Dasar di Puskesmas } \\
\text { Kecamatan Cinere }\end{array}$ & 387.696 .000 & 595.731 .000 & 983.427 .000 \\
\hline $\begin{array}{l}\text { Pelayanan Kesehatan Dasar di Puskesmas } \\
\text { Kecamatan Limo }\end{array}$ & 242.954 .000 & 737.046 .000 & 980.000 .000 \\
\hline $\begin{array}{l}\text { Pelayanan Kesehatan Dasar di Puskesmas } \\
\text { Kecamatan Cipayung }\end{array}$ & 181.486 .000 & 818.514 .000 & 1.000 .000 .000 \\
\hline TOTAL & 4.245 .892 .000 & 9.589.113.000 & 13.835 .005 .000 \\
\hline
\end{tabular}


Tabel 4 Costing SPM Biaya Operasional Bidang Kesehatan Jenis Layanan Dasar Hipertensi, Diabetes Melitus dan Gangguan Jiwa di Depok Tahun 2018-2020

\begin{tabular}{ccccccc}
\hline \multirow{2}{*}{$\begin{array}{c}\text { Jenis Layanan } \\
\text { Dasar (JLD) }\end{array}$} & $\begin{array}{c}\text { Biaya Total } \\
(\mathbf{R p})\end{array}$ & $\begin{array}{c}\text { Biaya Satuan } \\
(\mathbf{R p})\end{array}$ & $\begin{array}{c}\text { Biaya Total } \\
(\mathbf{R p})\end{array}$ & $\begin{array}{c}\text { Biaya Satuan } \\
(\mathbf{R p})\end{array}$ & $\begin{array}{c}\text { Biaya Total } \\
(\mathbf{R p})\end{array}$ & $\begin{array}{c}\text { Biaya Satuan } \\
(\mathbf{R p})\end{array}$ \\
\cline { 2 - 7 } & $\mathbf{2 0 9 . 6 2 1 . 1 4 6}$ & 10.716 & 992.791 .719 & 12.889 & 1.073 .403288 & 13.669 \\
\hline Hipertensi & 52.074 & 1.237 .114 .767 & 56.212 & 1.361 .470 .052 & 60.679 \\
\hline Diabetes Melitus & 1.134 .136 .935 & 63.815 & 226.482 .086 & 55.292 & 241.958 .374 & 57.143 \\
\hline Gangguan Jiwa & 252.849 .374 & 63019 & \\
\hline
\end{tabular}

Tabel 5. Rekapitulasi Total Biaya Operasional Pelayanan Dasar Hipertensi, Diabetes Melitus dan Gangguan Jiwa berdasarkan Costing SPM

\begin{tabular}{|c|c|c|c|c|}
\hline JPD & Jenis Pelayanan Dasar & 2018 & 2019 & 2020 \\
\hline \multirow[t]{4}{*}{8} & Pelayanan Kesehatan Hipertensi & 809.621 .146 & 992.791 .719 & 1.073 .408 .288 \\
\hline & I. Penyelenggaraan Pelayanan SPM Kesehatan & 798.478 .642 & 902.189 .921 & 979.176 .653 \\
\hline & $\begin{array}{l}\text { II. Penyelenggaraan Pelatihan SDM SPM- } \\
\text { Kesehatan }\end{array}$ & - & 38.114 .976 & 39.810 .591 \\
\hline & $\begin{array}{l}\text { III. Penyediaan Alat Kesehatan dan Pedoman } \\
\text { Kerja SPM Kesehatan }\end{array}$ & 11142504 & 52486822 & 54.421 .044 \\
\hline \multirow[t]{4}{*}{9} & $\begin{array}{l}\text { Pelayanan Kesehatan } \\
\text { Melitus }\end{array}$ & 1.124.136.935 & 1.237 .114 .767 & 1.361.470.052 \\
\hline & $\begin{array}{l}\text { I. Penyelenggaran Pelayanan Kesehatan SPM } \\
\text { Kesehatan }\end{array}$ & 1.124.136.935 & 1.237.114.767 & 1.361 .470 .052 \\
\hline & $\begin{array}{l}\text { II. Penyelenggaraan Pelatihan SDM SPM } \\
\text { Kesehatan }\end{array}$ & - & - & - \\
\hline & $\begin{array}{l}\text { III. Penyediaan alat kesehatan dan Pedoman Kerja } \\
\text { SPM Kesehatan }\end{array}$ & - & - & - \\
\hline \multirow[t]{5}{*}{10} & $\begin{array}{l}\text { Pelayanan Kesehatan Orang dengan Gangguan } \\
\text { Jiwa (ODGJ) Berat }\end{array}$ & 262.849.374 & 226.482 .096 & 241.978.354 \\
\hline & $\begin{array}{l}\text { I. Penyelenggaraan Pelayanan Kesehatan SPM } \\
\text { Kesehatan }\end{array}$ & 212.315 .374 & 226.482 .096 & 214.978 .354 \\
\hline & $\begin{array}{l}\text { II. Penyelenggaraan Pelatihan SDM SPM } \\
\text { Kesehatan }\end{array}$ & 40.534 .000 & - & - \\
\hline & $\begin{array}{l}\text { III. Penyediaan Alat Kesehatan dan Pedoman } \\
\text { Kerja SPM Kesehatan }\end{array}$ & - & - & - \\
\hline & Total Biaya SPM (JPD 8, JPD 9, JPD 10) & 2.816.607.455 & 2.456.388.581 & 2.676.856.694 \\
\hline
\end{tabular}

\section{Hasil Perhitungan costing SPM}

Tabel 4 menyajikan tentang biaya yang dikeluarkan oleh masing-masing penderita Hipertensi, Diabetes Melitus dan Gangguan Jiwa. Dengan demikian jika jumlah kasus/penderita diketahui dengan pasti melalui hasil pendataan PIS PK, maka dapat diketahui jumlah biaya yang dibutuhkan untuk pembiayaan PTM sesuai SPM.

Kebutuhan biaya operasional dari setiap pelayanan dasar PTM (Hipertensi, Diabetes Melitus dan Gangguan Jiwa) masing-masing dibedakan menjadi 3 jenis biaya penyelenggaraan yaitu jenis biaya penyelenggaraan pelayanan SPM-Kesehatan, jenis biaya penyelenggaraan pelatihan SDM SPM-Kesehatan, dan jenis biaya penyediaan alat kesehatan dan pedoman kerja SPM-Kesehatan.

Dari hasil perhitungan costing SPM khususnya jenis pelayanan dasar (JPD) Hipertensi, JPD Diabetes Melitus dan JPD Gangguan Jiwa pada tahun 2018 adalah sebesar Rp 2.816. 607.455, tahun 2019 sebesar Rp 2.456.388.581 dan tahun 2020 sebesar Rp 2.676.856.954 (Tabel 5). Total biaya penyelenggaran SPM di atas merupakan hasil perhitungan biaya yang harus disediakan oleh pemerintah daerah dalam hal ini Kota Depok. Total biaya tersebut belum menentukan sumber biaya 
Tabel 6 Prosentase Biaya SPM Jenis Pelayanan Dasar Hipertensi (JPD 8),

Diabetes Melitus (JPD 9) dan Gangguan Jiwa (JPD 10)Terhadap APBD Kota Depok Tahun 2018-2020

\begin{tabular}{|c|c|c|c|c|}
\hline \multirow{2}{*}{ No. } & \multirow{2}{*}{ Uraian } & \multicolumn{3}{|c|}{ Tahun } \\
\hline & & 2018 & 2019 & 2020 \\
\hline 1 & $\begin{array}{l}\text { Total Biaya Operasional (JPD 8, JPD } 9 \& \\
\text { JPD 10) }\end{array}$ & 2.186.607.455 & 2.456 .388 .581 & 2.637 .046 .103 \\
\hline 2 & Total APBD Kota Depok & 3.083 .490 .118 .772 & 3.197 .823 .703 .874 & 3.365 .327 .575 .314 \\
\hline 3 & $\begin{array}{l}\text { APBD Kota Depok Belanja Langsung (BL) } \\
\text { / Non Gaji }\end{array}$ & 1.837.233.260.898 & 1.975 .075 .597 .816 & 2.133 .643 .768 .672 \\
\hline 4 & Total APBD Kesehatan Kota Depok & 429.658 .492 .180 & 446.458 .492 .180 & 458.866 .674 .825 \\
\hline 5 & $\begin{array}{l}\text { APBD Kesehatan Kota Depok Belanja } \\
\text { Langsung }\end{array}$ & 158.482 .767 .500 & 164.720 .512 .150 & 169.270 .143 .600 \\
\hline 6 & $\begin{array}{l}\text { \% APBD Kesehatan Kota Depok Bl } \\
\text { Terhadap APBD Kota Depok Belanja } \\
\text { Langsung }\end{array}$ & $8,63 \%$ & $8,34 \%$ & $7,93 \%$ \\
\hline 7 & $\begin{array}{l}\% \text { APBD Kesehatan Kota Depok Terhadap } \\
\text { APBD Kota Depok }\end{array}$ & $13,93 \%$ & $13,96 \%$ & $13,64 \%$ \\
\hline 8 & $\begin{array}{l}\text { \% Biaya SPM (JPD 8, JPD } 9 \text { \& JPD 10) } \\
\text { Terhadap APBD Kesehatan Kota Depok BL }\end{array}$ & $1,38 \%$ & $1,49 \%$ & $1,56 \%$ \\
\hline 9 & $\begin{array}{l}\text { \% Biaya SPM (JPD 8, JPD } 9 \text { \& JPD 10) } \\
\text { Terhadap APBD Kota Depok Belanja } \\
\text { Langsung }\end{array}$ & $0,12 \%$ & $0,12 \%$ & $0,12 \%$ \\
\hline
\end{tabular}

Tabel 7 Kemampuan Biaya Pelayanan Dasar PTM dan Kegiatan yang Menunjang PIS PK

\begin{tabular}{lccc}
\hline \multicolumn{1}{c}{ Uraian } & \multicolumn{2}{c}{ Tahun } & $\mathbf{2 0 2 0}$ \\
\cline { 2 - 4 } & $\mathbf{2 0 1 8}$ & $\mathbf{2 0 1 9}$ & 169.270 .143 .600 \\
\hline $\begin{array}{l}\text { APBD Kesehatan Belanja Langsung (BL) Kota } \\
\text { Depok }\end{array}$ & 158.482 .767 .500 & 164.720 .512 .150 & 535.056 .000 \\
\hline Anggaran yang menunjang kegiatan PIS PK & 435.056 .000 & 535.056 .000 & 481.877 .500 \\
\hline $\begin{array}{l}\text { Anggaran Penyakit Tidak Menular dan } \\
\text { Kesehatan Jiwa }\end{array}$ & 366.051 .000 & 505.996 .800 & 2.676 .856 .694 \\
\hline Total Biaya SPM (JPD 8, JPD 9 \& JPD 10) & 2.186 .607 .455 & 2.456 .388 .581 & 145.234 .536 \\
\hline $\begin{array}{l}\text { Belanja SPM (JPD 8, JPD 9 \& JPD 10) Yang Bisa } \\
\text { Dibiayai dari Sumber APBD Murni }\end{array}$ & 98.517 .366 & 138.338 .616 & 77.676 .111 \\
\hline $\begin{array}{l}\text { Belanja SPM (JPD 8, JPD 9 \& JPD 10) Yang Bisa } \\
\text { Dibiayai dari Sumber DAK Non Fisik }\end{array}$ & 74.426 .773 & 73.897 .392 & $0,32 \%$ \\
\hline $\begin{array}{l}\text { \% anggaran yang menunjang kegiatan PIS PK } \\
\text { terhadap APBD Kesehatan BL Kota Depok }\end{array}$ & $0,27 \%$ & $0,32 \%$ & $0,28 \%$ \\
\hline $\begin{array}{l}\text { \% Anggaran PTM dan Kes. Jiwa tehadap APBD } \\
\text { Kesehatan BL Kota Depok }\end{array}$ & $0,23 \%$ & $0,31 \%$ & $30,14 \%$ \\
\hline $\begin{array}{l}\text { \%Belanja SPM (JPD8, JPD 9 dan JPD 10) dari } \\
\text { Sumber APBD Murni terhadap Anggaran PTM }\end{array}$ & $26,91 \%$ & $27,34 \%$ & $\mathbf{2}$ \\
\hline
\end{tabular}

yang membiayainya. Sumber biaya dapat ditentukan dengan melihat setiap langkah kegiatan dari setiap JPD dalam perhitungan biaya SPM setiap tahunnya, sehingga dapat ditentukan sumber pembiayaannya.

Kota Depok mampu untuk melaksanakan SPM bidang kesehatan khusus jenis pelayanan dasar Hipertensi, Diabetes Melitus dan Gangguan Jiwa karena hanya 1,38\% APBD Kesehatan belanja langsung (Non Gaji) Kota Depok dan hanya 0.12\% APBD belanja langsung (Non Gaji) yang dipergunakan dalam melaksanakan SPM Jenis pelayanan kesehatan Hipertensi, Diabetes Melitus dan Gangguan Jiwa (Tabel 6). Hal ini berarti bahwa Depok hanya memerlukan 1,38\% dari belanja kesehatannya untuk memenuhi kebutuhan biaya pelayanan Hipertensi, DM dan Gangguan Jiwa. Sedangkan APBD Kesehatan belanja langsung (Non Gaji) Kota Depok masih kurang dari 10\% jika dibandingkan dengan APBD Kesehatan belanja langsung (Non Gaji) Kota Depok. Hal ini disebabkan 
karena belanja kesehatan RSUD kota Depok belum dihitung.

Tabel 7 menunjukkan bahwa anggaran PTM (Hipertensi dan Diabetes Melitus) serta belanja pelayanan kesehatan orang dengan Gangguan Jiwa di Kota Depok pada tahun 2018 cukup untuk membiayai pelaksanaan SPM khusus JPD kesehatan Hipertensi, JPD kesehatan Diabetes Melitus dan JPD kesehatan Gangguan Jiwa. Namun perlu diingat bahwa kegiatan pada SPM merupakan kegiatan minimal yang harus dilaksanakan oleh Kota Depok. Dengan demikian anggaran belanja SPM juga merupakan anggaran minimal yang harus disediakan, karena masih banyak kegiatan/pelayanan kesehatan PTM di luar SPM.

\section{Indikator Kesiapan Pelaksanaan PIS PK}

Berdasarkan uraian kesiapan pembiayaan Hipertensi, Diabetes Melitus dan Gangguan Jiwa untuk mendukung pelaksanaan PIS PK, variable komitmen dan kebijakan, sumber daya manusia, sistem informasi kesehatan, perencanaan, peta jalan, dan ketersediaan pembiayaan yang ditemukan dalam penelitian ini. Untuk itu dilakukan skoring untuk menilai apakah Kota Depok memiliki kesiapan maksimal, kesiapan minimal atau tidak siap dalam pelaksanaan PIS PK. Indikator kesiapan dikategorikan berdasarkan variabel yang diteliti dalam studi ini (Tabel 8).

Tabel 8. Indikator Kesiapan Pelaksanaan PIS PK

\begin{tabular}{clccc}
\hline No & \multicolumn{1}{c}{ Indikator } & $\begin{array}{c}\text { Tidak } \\
\text { Ada }\end{array}$ & $\begin{array}{c}\text { Belum } \\
\text { Lengkap }\end{array}$ & Lengkap \\
\hline 1 & Regulasi & $\sqrt{ }$ & \\
2 & Komitmen & $\sqrt{ }$ & $\sqrt{ }$ \\
3 & Kebijakan Program & & $\sqrt{ }$ & \\
4 & Sistem Informasi & & \\
5 & Kesehatan & & \\
6 & Ketersediaan Anggaran & $\sqrt{ }$ & $\sqrt{ }$ \\
7 & Perencanaan & & $\sqrt{ }$ \\
8 & Peta Jalan & & 7 \\
9 & Identifikasi Kegiatan & & $\mathbf{1}$ \\
10 & Realisasi Anggaran & $\sqrt{ }$ & \\
\hline & Total & 2 &
\end{tabular}

Kesiapan 10 indikator yang sudah ada, meskipun belum lengkap, sudah dapat menunjang pelaksanaan PIS PK, namun tetap perlu diupayakan agar menjadi lengkap sehingga dapat optimal dan realistis dalam mendukung pelaksanaan PIS PK. Dengan demikian, berdasarkan tabel diatas, Kota Depok dapat dikategorikan belum siap dalam pelaksanaan
PIS PK terutama dalam hal kesiapan pembiayaannya.

\section{Pembahasan}

Pemerintah Kota Depok telah merencanakan kegiatan PIS PK dengan baik, terlihat pada tercantumnya kegiatan PIS PK dalam Renstra Perubahan tahun 20192021 yang merupakan penerjemahan dan penguraian lebih terperinci dari RPJMD Kota Depok 2019-2021.

Disusunnya Renstra Perubahan tersebut membuktikan adanya komitmen Pemerintah Kota Depok terhadap program prioritas. . Kesiapan Depok dalam melaksanakan PIS PK tidak cukup hanya dengan memasukkan dalam Renstra saja. Hal terpenting adalah bagaimana Pemerintah kota Depok melaksanakan PIS PK. Untuk itu diperlukan komunikasi dan kerja sama antara Dinas Kesehatan dan Puskesmas sebagai pelaksana. Laelasari (2017) dalam penelitiannya tentang evaluasi kesiapan PIS PK di beberapa kabupaten/kota, mengungkapkan bahwa dengan adanya komitmen dari Dinas Kesehatan, maka Puskesmas juga akan memiliki komitmen tinggi dalam menyelesaikan target pendataan di wilayah kerjanya.

Wibowo (2017) mengatakan bahwa berdasarkan hasil evaluasi PIS PK di beberapa daerah, dukungan dan komitmen Pemerintah Daerah serta lintas sektor untuk PIS PK belum optimal dilihat dari belum adanya SK atau peraturan setingkat gubernur atau bupati/walikota. Rencana tindak lanjut yang akan dilakukan adalah mendorong komitmen Pemda dengan memperkuat advokasi termasuk agar dikeluarkannya SK Gubernur ataupun Bupati/ Walikota untuk pelaksanaan PIS PK. Kota Depok sendiri belum mempunyai peraturan setingkat Gubernur atau Bupati/Walikota tentang PIS PK, baru sebatas Keputusan Kepala Dinas Kesehatan.

Hasil penelitian ini menunjukkan bahwa web aplikasi keluarga sehat merupakan satusatunya sistem informasi yang ada saat ini yang digunakan dalam kegiatan pelaporan PIS PK, dan itu disediakan oleh pihak eksternal dalam hal ini Pusdatin Kementerian Kesehatan. Menurut Wibowo (2017), solusi yang ditawarkan adalah memisahkan aplikasi dengan data base, memperbesar kapasitas pada perangkat pengolah data aplikasi keluarga sehat dan improvisasi logic aplikasi keluarga sehat untuk mempercepat penghitungan IKS Wilayah. Kendala serupa berupa kesulitan input data dialami juga oleh daerah lain seperti misalnya Lampung, Bandung, Serang, Gowa dan Manado. Kementerian Kesehatan dalam hal ini Pusat Data dan Informasi (Pusdatin) harus lebih siap dan tanggap menghadapi 
keluhan terkait web aplikasi keluarga sehat.

Menurut sebuah penelitian penggunaan data kesehatan di California, logic model menyediakan panduan yang spesifik dan komprehensif untuk meningkatkan permintaan dan penggunaan data untuk merancang, memantau dan mengevaluasi intervensi dalam pengambilan keputusan (Nutley, T \& Reynolds, H, 2013). Hasil penelitian ini menunjukkan bahwa kekurangan SDM untuk melakukan pendataan PIS PK serta sedikitnya pelatihan merupakan isu utama pelaksanaan PIS PK di Kota Depok dalam aspek SDM. Hal ini sejalan dengan penelitian yang dilakukan Ghozali (2017) bahwa SDM secara kualitas dan kuantitas masih belum mencukupi untuk implementasi PIS PK di Bandung, Keterbatasan kualitas dan kuantitas SDM berpengaruh pada capaian keluarga yang terdata.

Hal ini disebabkan oleh karena keterbatasan jumlah staf di Puskesmas jika harus mengadakan kegiatan di luar gedung dan di dalam gedung dalam waktu bersamaan, sementara banyak program yang menjadi tanggung jawab serta tugas tambahan administratif.. Namun jika kegiatan luar gedung dilakukan di luar jam kerja selain keterbatasan waktu juga ketiadaan biaya lembur. Oleh karena itu perlu inovasi dan kerja sama dengan pihak swasta maupun universitas-universitas.

Dalam hal aspek SDM. baik kualitas maupun kuantitas, kesiapan Depok belum optimal, sehingga diperlukan peran serta masyarakat berupa pemberdayaan masyarakat. Hal ini disebabkan karena kekurangan anggaran dan SDM baik terlatih maupun tidak. Untuk menyiapkan SDM terlatih tentunya membutuhkan anggaran yang tidak sedikit dan saat ini belum ada sumber dana yang mengakomodir pelatihan SDM di Depok.

Menurut penelitian Litbangkes (2017) tentang pelaksanaan PIS PK di Lampung, keterbatasan SDM dapat diatasi dengan melakukan On Job Training pada staf Puskesmas yang be lum dilatih Bapelkes, pelatihan kader terpilih untuk membantu wawancara, melakukan kunjungan rumah tidak hanya di jam kerja namun juga di luar jam kerja dengan konsekuensi tambahan uang lembur, serta kerja sama dengan Poltekes atau Perguruan Tinggi di lingkungan Puskesmas. Alternatif solusi SDM untuk mempermudah pendataan adalah memberdayakan masyarakat dalam hal ini kader PTM sebagai pendamping saat kunjungan rumah.

Dalam hal pendanaan, kegiatan PIS PK belum dianggarkan di APBD tahun 2018. Pada saat merancang kegiatan dan anggaran di tahun sebelumnya, PIS PK belum menjadi prioritas. Selain itu, jumlah anggaran yang diterima oleh daerah baru diketahui pada tahun berikutnya di mana beberapa kegiatan sudah berjalan. Anggaran yang digunakan untuk kegiatan PIS PK di tahun 2018 ini bersumber dari DAK Non Fisik. Belanja kesehatan untuk kegiatan yang menunjang PIS PK sebesar 0,27\% dari APBD Kesehatan belanja langsung kota Depok, ini berarti Depok mampu dan siap untuk melaksanakan PIS PK. Belanja kesehatan yang menunjang kegiatan PIS PK hanya berupa sosialisasi, pendataan dan monev, dan tidak ada intervensi khusus PTM. Jumlah belanja PIS PK hanya digunakan untuk manajerial saja, sementara kegiatan yang terkait intervensi indikator keluarga sehat tersebar di semua bidang di Dinas Kesehatan dan Puskesmas.

Dari hasil perhitungan costing SPM, total biaya yang dibutuhkan untuk pelayanan Hipertensi di tahun 2018 menurut jenis kegiatannya menunjukkan bahwa total biaya yang dibutuhkan untuk pelayanan Hipertensi adalah Rp 809.621.145. Dengan dana yang ada tersebut, di mana kebutuhan setiap orang akan pelayanan Hipertensi di tahun 2018 sebesar Rp 10.716 artinya ada 79.561 orang penderita Hipertensi yang dapat tertangani. Total biaya yang dibutuhkan untuk pelayanan Diabetes Melitus tahun 2018 sebesar rp 1.134.136.935, di mana kebutuhan setiap orang akan pelayanan Diabetes Melitus sebesar rp 52.074 artinya ada 21.779 orang penderita Diabetes Melitus yang dapat tertangani. Total biaya yang dibutuhkan untuk pelayanan dasar Gangguan Jiwa adalah Rp 252.849.374 dengan kebutuhan setiap orang akan pelayanan Gangguan Jiwa sebesar Rp 63.815. Hal ini berarti bahwa ada 3.962 orang penderita Gangguan Jiwa yang dapat tertangani.

Dalam hal pembiayaan Hipertensi, Diabetes Melitus dan Gangguan Jiwa, Kota Depok mampu untuk melaksanakan SPM bidang kesehatan khusus jenis pelayanan dasar Hipertensi, Diabetes Melitus dan Gangguan Jiwa karena hanya 1,38\% APBD Kesehatan Belanja Langsung (Non Gaji) Kota Depok yang dipergunakan dalam melaksanakan Pelayanan Kesehatan Hipertensi, Diabetes Melitus dan Gangguan Jiwa sesuai SPM. Hal ini berarti bahwa Depok hanya memerlukan 1,38\% dari belanja kesehatannya untuk memenuhi kebutuhan biaya pelayanan Hipertensi, Diabetes Melitus dan 


\section{Gangguan Jiwa.}

Kota Depok belum selesai melakukan pendataan, sehingga belum diketahui jumlah total kasus penderita PTM dan belum dilakukan intervensi lanjut. Target PIS PK sesuai peta jalan Depok adalah 50\% di tahun 2018 serta mencapai 100\% total coverage di tahun 2019, di mana PTM termasuk dalam salah satu indikatornya. Ketika total coverage tercapai, maka akan dapat diketahui jumlah kasus penderita Hipertensi, DM dan Gangguan Jiwa, sehingga dapat diketahui gambaran jumlah biaya yang harus disediakan oleh Kota Depok sesuai perhitungan costing SPM. Salah satu keberhasilan SPM adalah tercapainya indikator SPM (100\%), di mana indikator SPM termasuk juga dalam indikator PIS PK. Dapat dikatakan bahwa PIS PK merupakan awal dan salah satu jalan untuk mencapai total coverage SPM.

\section{Kesimpulan}

Kota Depok belum siap dalam pelaksanaan PIS PK terutama dalam hal komitmen, SDM dan kesiapan pembiayaannya. Masalah utama adalah ketersediaan pembiayaan dari DAK Non Fisik, yang belum ada hingga triwulan pertama. Hal ini dikarenakan Permenkes tentang Petunjuk teknis penggunaan dana DAK Non Fisik terbit setelah APBD ditetapkan. Proses perencanaan belum optimal karena PIS PK baru masuk dalam Renstra Perubahan tahun 20192021. Kota Depok memiliki kemampuan untuk melaksanakan SPM bidang kesehatan khusus jenis pelayanan dasar Hipertensi, Diabetes Melitus dan Gangguan Jiwa karena hanya 1,38\% APBD Kesehatan Belanja Langsung (Non Gaji) Kota Depok dan hanya $0.12 \%$ APBD Belanja Langsung (Non Gaji) yang dipergunakan dalam melaksanakan SPM jenis pelayanan kesehatan Hipertensi, Diabetes Melitus dan Gangguan Jiwa.

\section{Daftar Pustaka}

Aditama. 2005. Catatan Kegiatan Penelitian, Terapan, dan Kesehatan Masyarakat. Jakarta: Balitbangkes.

Armiatin. 2015. Manajemen Penyakit Diabetes Untuk Minimalkan Pengeluaran Biaya. 10 Maret 2018 <http://mutupelayanankesehatan.net/index.php/ sample-levels/19-headline/1856-manajemenpenyakit - diabetes - un tuk-minimalkanpengeluaran-biaya $>$.

Badan Penelitian dan Pengembangan Kementerian Kesehatan. 2013. "Riset Kesehatan Dasar
RISKESDAS 2013” 15 Januari 2015. <http:// www.depkes.go.id/resources/download/ general/Hasil Riskesdas 2013.pdf $>$. Ferdiansyah, D. 2016. Metode Pendekatan Keluarga, terobosan Baru Dalam Pembangunan Kesehatan di Indonesia. 1(4): 5-8. Ghozali, A. 2017. Analisis Implementasi PIS PK di Kabupaten Bandung. Universitas Indonesia, Jakarta. Kementerian Kesehatan. 2016a. Buku Pedoman Umum Program Indonesia Sehat dengan Pendekatan Keluarga. 8 Oktober 2017 <http://www.depkes. go.id/resources/download/lain/Buku Program Indonesia Sehat dengan Pendekatan Keluarga.pdf>. Kementerian Kesehatan. 2016b. Permenkes Nomor 39 tahun 2016 tentang Program Indonesia Sehat dengan Pendekatan Keluarga. Jakarta.

Kementerian Kesehatan, P. data dan I. 2017. Hasil Pendataan Keluarga Sehat dalam Aplikasi Keluarga Sehat. 30 Oktober 2017. <http://www.pusdatin. kemkes.go.id/article/view/17091900001/ hasil-pendataan-keluarga-sehat-dalam-aplikasikeluarga-sehat.html>.

Kruk, M. E., Porignon, D., Rockers, P. C. and Van Lerberghe, W. 2010. The contribution of primary care to health and health systems in low-and middleincome countries: A critical review of major primary care initiatives. Social Science \& Medicine. 70(6): 904-911.

Laelasari, E., Anwar, A. and Soerachman, R. 2017. Evaluasi Kesiapan Pelaksanaan Program Indonesia Sehat Dengan Pendekatan Keluarga. 27 Mei 2018. <https://media.neliti.com/ media/publications/222923-evaluasi-kesiapanpelaksanaan-program-in.pdf>

Litbangkes. 2017. Hasil (Sementara) Riset Implementasi PIS PK di Kabupaten Lampung Selatan. Forum Ilmiah Tahunan IAKMI III.

Nutley, T \& Reynolds, H. W. 2013. Improving the use of health data for health system strengthening. Global health action. 6 (1)

Shivalli, S., Majra, J. P., Akshaya, K. M. and Qadiri, G. J. 2015. Family Centered Approach in Primary Health Care: Experience from an Urban Area of Mangalore, India. The Scientific World Journal. Hindawi, p. 1-8.

Swanson, K. A., Swanson, J. M., Gill, A. E. and Walter, C. 1995. Primary care in Cuba: A public health approach. Health Care for Women International. 16(4): 299-308.

Wibowo, Bambang. 2017. Progress Report Program 
Indonesia Sehat Dengan Pendekatana Keluarga. World Health Organization. 2015. Noncommunicable Jakarta. 28 Maret 2018. <http://dinkes.babelprov. Diseases Progress Monitor 2015. WHO. World go.id/sites/default/files/dokumen/bank_data/ Health Organization, p. 232.

BAHAN RAKORPIMPAR_DIRJEN YANKES_

fin_210717_EDITBINWIL.pdf> 